\title{
A Study of Vehicular Information Network Architecture based Named Data Networking (NDN)
}

\author{
Kanwalpreet Kaur \\ M.Tech Scholar Department of Computer \\ Science \& Engineering, Amritsar College of \\ Engineering \& Technology, Amritsar
}

\author{
Sandeep Kad \\ Associate Professor, Department of Computer \\ Science \& Engineering, Amritsar College of \\ Engineering \& Technology, Amritsar
}

\begin{abstract}
Vehicular Ad hoc Network (VANETs) technologies have recently been getting plenty of attention in these years. The VANETs goals to put into practice an limitless application connected to cars, site visitors information, motorists, guests, along with pedestrians. But, inter-vehicular connection (IVC) in the vehicular facts network remains in line with the TCP/IP venture stack which might be perhaps not really efficient together with scalable. To deal with the accomplishment and scalability issues in the IVC, we use name facts networking (NDN) Throughout NDN the conclusion user only concern about the necessary stuff and gives no targeted the number of location in the content. The NDN style and design is more suited to the IVC scenario having its hierarchical stuff labeling prepare and changing material access and caching assistance. The whole objective in the report would be to gauge the benefits of the NDN process within the accessible approaches. Also this specific report ultimately winds up with the several limits of earlier approaches.
\end{abstract}

\section{Keywords}

Named data networking (NDN), Vehicular communication, Internet of things(IOT)

\section{INTRODUCTION}

Vehicular Ad hoc Network (VANET) is usually accepted just as one exceptional form of Mobile Ad hoc Network (MANET), which get interest of several researchers. In VANET just about every vehicle acts like a switch to alter data involving different nodes inside network. It is wonderful for vehicle-to-vehicle $(\mathrm{V} 2 \mathrm{~V})$ and infrastructure-to-vehicle (IVC) verbal communication. This almost networks is situated in traffic control applications, protection applications, driver assistance in addition to location primarily based services. In VANETs power consumption in addition to storage capacity usually are not limited and the position of the nodes might be determined by the use of GPS [9]. VANET has unique attributes like higher mobility using the constraint regarding road topology, initially low market penetration ratio, unbounded network size, infrastructure support which differ the item from MANET. From the previous mentioned features, it's observed that conventional MANET routing protocols have difficulties to locate stable routing paths throughout VANET circumstances [9]. For that reason, many scientists have centered on advising suitable routing protocols to handle the more dynamic nature of VANET.

\section{COMPONENTS OF VANET}

VANET is usually an autonomous personal organizing cellular network. VANETs contains following organizations:

1. Cars: Vehicles would be the nodes regarding vehicular multilevel. VANET tackle the cellular communication involving vehicles (V2V) in addition to between cars and structure access stage.

2. Commercial infrastructure: Infrastructure in connection with outside setting includes path side starting station. Base stations would be the roadside unit and maybe they are located from dedicated place like junctions or even near auto parking spaces. Their primary functions are to enhance the communication section of the ad hoc multilevel by re-allocating the details to others and also to run safety request like low bridge warning, accident warning etc.

3. Conversation channels: Radio waves are a sort of electromagnetic rays with wavelengths inside electromagnetic selection longer compared to infrared gentle. Radio waves have frequencies via $190 \mathrm{GHz}$ to $3 \mathrm{Khz}$. Radio distribution model plays a solid role inside performance of an protocol to determine the number regarding nodes in one impact domain [19]. There are three types of vehicular communication system:-

\subsection{Vehicle to Vehicle Communication}

1) The vehicle-to-vehicle (V2V) communication platform is at reality a typical research topic, with many approaches. Several approaches take place, each that features a considerably different focus [9]. Traffic security enhancement could be the driving aspect in several techniques, typically ultimately causing a response where sensor data from autos and RSU can be used for supplying crash and temp alert to roadside items and autos.

2) Vehicle-to-vehicle (V2V) sales and marketing communications comprises an instant network in which automobiles deliver messages as well as information relating to what these are doing. This data would include speed, location, direction of journey and too little stability. Vehicle-to-vehicle engineering employs dedicated shortrange communications (DSRC) [9]. V2V is merely a mesh network that means every node (car, clever traffic sign, etc) can send, get and again sends the signals. It makes use of the multi- hop/multi throw technique.

3) It works by using two kinds of broadcasting

i) Naive broadcasting

ii) Intelligent broadcasting

2.2 Vehicle to Infrastructure (V2I) Communication

1. The V2I process represents a new practical solution for a lot of applications to bridge the actual inherent network fragmentation in which exists in the multi-hop network established around moving cars through expensive connectivity structure [19]. 


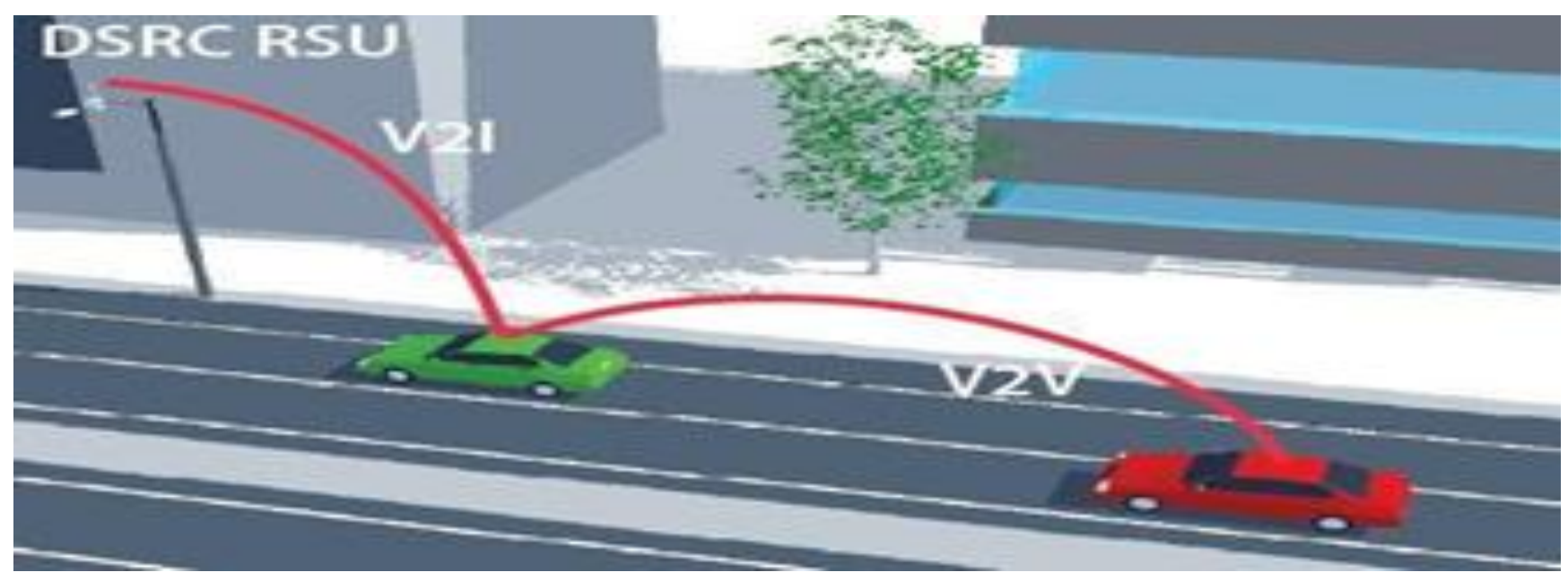

Fig 1. Communication in vehicular network [19]

2. Vehicle-to-Infrastructure (V2I) communications for protection is the wireless exchange of important safety in addition to operational info between cars and roadway infrastructure, intended primarily in order to avoid motor auto crashes [19]. V2I communications for security can be quite a main investigation program from the Intelligent Travelling Systems Articulation Program Place of work (ITS JPO) program in the U. S. Department regarding Transportation's (U. S. DOT) Analysis and Progressive Technology Current administration (RITA) [19].

3. It offers high bandwidth link to vehicle as well as roadside equipment.

4. Roadside units transmitted messages.

\subsection{Vehicle to Road Side (V2R) Communication}

1. Inside V2R connection vehicles can easily communicate having fixed infrastructure alongside of the trail in order to provide person communication and also information providers.

2. It has to be noted that architecture doesn't rely around the infrastructure in order to operate but instead exploits it to enhance the network performance.

3. A cross network significance the living of the two vehicles and also roadside equipment.

\section{APPLICATIONS OF VEHICULAR INFORMATION NETWORK}

The particular involved communication cases tend to be as follows-

1. Vehicles can certainly distribute the sensed data from the network by utilizing push or pull based techniques [18].

2. Vehicles helps keep touching local vehicles within an ad hoc approach or through the communication structure that you can be get or send out traffic, road condition info, or multimedia data [18].

3. An aggregator (such as a server) [18] work extremely well not merely to gather and also process data but in addition used to provide processed info to additional vehicles on demand.

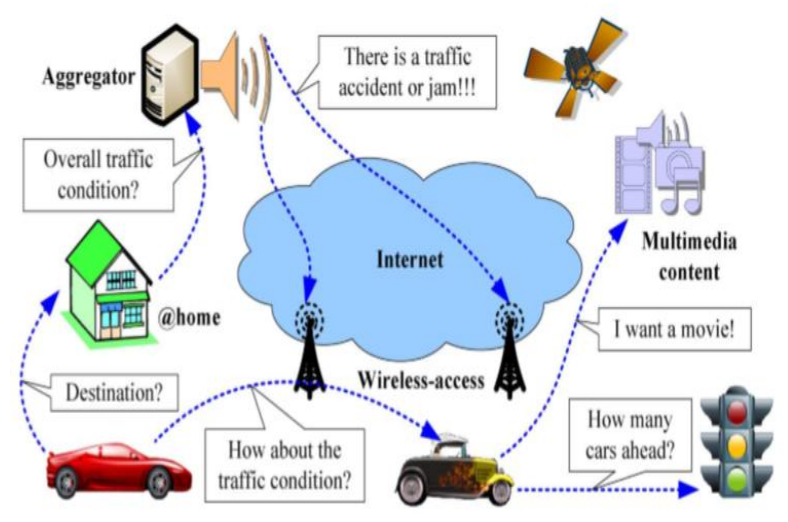

Fig 2 .Application of vehicular information network [18]

\section{NAMED DATA NETWORKING}

Named Data Networking (NDN) can be a new internet architecture that concentrates mostly on name-centric networking [11]. Named Data Networking is usually proposed recently considering the fact that clean-slate network architecture regarding future internet, that ignore focuses on "where" the data is found, but "what" the data (content) should be applied. NDN works by using names to tell apart every little bit of contents as opposed to IP addresses for hardware devices set up on IP network [11]. An NDN name is hierarchically structured that has explicitly delimited elements.

\section{USE OF NAMED DATA NETWORKING IN VANETS}

Throughout NDN, content including movie is usually divided into a couple of individually referred to as smaller content material objects. Content thing names are generally hierarchical along with human-readable every bit as the domains in the current Internet. The communications within NDN are generally consumer-initiated [18]. Hence, a consumer might retrieve someone content thing by transferring a signaling principle called any pursuit packet 
which often wills specifies your own name using the specified articles object. Every time a modem will get a desire packet and includes a copy using this type of content object in the local cache shop (CS), the router content back the info without much more propagating the eye packet. In circumstance the router isn't going to need the asked for content, it looks in the next-hop neighbors through the forwarding details base (FIB) to assist forward the eye packet to try and do the finest prefix match using the name versus its forwarding dining table. Whenever a Interest packet will be relayed, an NDN router retains the data in the pending awareness table (PIT) meaning that your response may perhaps be routed on the requester during the entire reverse way [18].

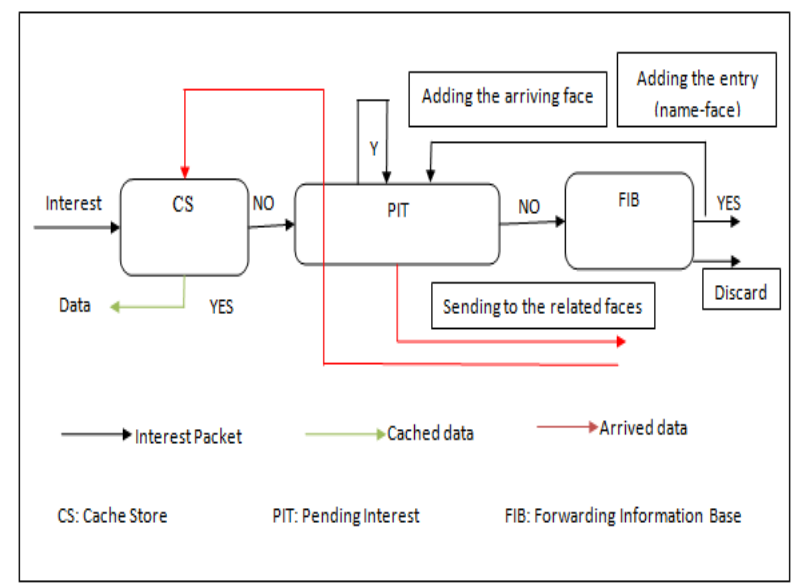

Fig 3. NDN communication principle [18]

\section{INTERNET OF THINGS (IOT)}

The world wide web of Factors (IOT) stand for the comprehensive vision the location where the 'things' by way of example for illustration everyday products, places in addition to environments are interconnected with one another via your current internet[22]. An illustration in this an uncomplicated IOT materials on the market today in a few homes is usually a thermostat that will determine every time people may occupy distinct rooms in addition to alter degrees of heating program, lighting along with functions within your house accordingly [22]. By widening the internet from "a 'network of interconnected computers to many networks about interconnected objects", the IOT will probably convey a huge in addition to intricate network of items. These units include sensors to calculate environment. friendly surroundings all around them, actuators which often physically react back inside their environment for example for illustration opening a family house, processors to regulate and shop the great information generated, nodes to be able to communicate the details and planners to considerably help manage your sets of these components [22].

\section{RELATED WORK}

Biswas, et 's. [1] offered a review of motorway cooperative lock up avoidance (CCA), which is usually an emerging power plant safety application when using the Dedicated Quick Range Discussion (DSRC) standard or a description with all the DSRC houses, we introduce the thought of CCA

along with implementation requirements within the context of any vehicle- to-vehicle quick network, primarily with all the Medium Obtain Control (MAC) plus the routing stage.
Koponen, et 's. [2] demonstrates internet functions evolved enormously off their original incarnation. The majority present World-wide-web utilization is actually information retrieval together with service entry, whereas your architecture has also been made all-around host-to-host applications for example telnet together with ftp. Now the many network stakeholders take advantage of middle boxes to enhance security together with accelerate software. Feldmann, et 's. [3] tells the many believe it is impossible to be able to resolve the problems facing current day Internet without having rethinking the main assumptions together with design models underlying the current houses. Therefore, a critical research effort remains initiated in the main issues Clean State Design with all the Internet's houses. In this paper everyone first gives all of the troubles another internet needs to address and it discuss approaches pertaining to finding doable solutions, along with Clean State Design. Eriksson, et 's. [4] using accessible Wi-Fi access within the trail may be very challenging. Network online connectivity within Cabernet is definitely both fleeting together with intermittent and that is suffering via high offer loss charges above this wireless sales channel. With your positive element, Wi-Fi details transfers, any moment available, can happen at broadband rates of speed. In this paper, everyone introduce a couple of new factors for increasing open Wi-Fi details delivery to help moving vehicles: The first, Rapid Wi-Fi, is only a sleek clientside process to find out end-to-end online connectivity, reducing imply connection time for it to significantly lower than 400 milliseconds, from a lot more than 10 seconds whenever using standard quick networking software package. To characterize just how much open Wi-Fi capacity offered to vehicular owners, we positioned Cabernet with a fleet about 10 taxis within the Boston position. Belimpasakis, et 's. [5] proposes an answer that will allow home managed content, entirely on home Personal computers or UPnP advertising servers, to get wanted to help remote potential buyers, for use. The device relies on a new proxy residing in the house circle that exports your multimedia content to many website syndication feed after having a Atom common protocol, that is certainly actually subsequently seen via compatible remote control buyers. A type of the process was built, with your proxy efficiency implemented with a house PC plus the remote potential buyers running on phone devices. Special attention remains paid for that social areas of content revealing, for allowing your home owner to help also ask other extra users to help remotely entry specific, home-based advertising containers, with a breeze and protected device build. Jacobson, et 's. [6] offers the circle use functions evolved to get dominated simply by content posting and admittance, while social network technology even now speaks basically of internet connections between managers. Accessing information and alternatives requires mapping via what in which users care about to your network's exactly where. We recent Content-Centric Marketing (CCN) which will treats con- tent being a primitive - decoupling position from persona, security together with access, together with retrieving information by tag. 


\section{COMPARISON TABLE}

Table 1: Comparison of Various Technique

\begin{tabular}{|c|c|c|c|c|c|}
\hline $\begin{array}{l}\text { Ref } \\
\text { No }\end{array}$ & Authors & Year & Technique & Features & Limitations \\
\hline [1] & Subir Biswas, et al & 2006 & $\begin{array}{l}\text { CCA: Enhancing Highway } \\
\text { Traffic Safety }\end{array}$ & $\begin{array}{l}\text { Performance sensitivity of CCA, } \\
\text { implementation issues. }\end{array}$ & $\begin{array}{l}\text { packet-routing protocols to } \\
\text { support an effective CCA } \\
\text { system with the DSRC } \\
\text { environment is not considered }\end{array}$ \\
\hline [2] & $\begin{array}{l}\text { Teemu Koponen, et } \\
\text { al }\end{array}$ & 2007 & $\begin{array}{l}\text { DONA: redesign of World } \\
\text { wide web naming along } \\
\text { with name image } \\
\text { resolution. }\end{array}$ & $\begin{array}{l}2 \text { Naming, World-wide-web } \\
\text { architecture, identify resolution, } \\
\text { info, middle containers }\end{array}$ & $\begin{array}{l}\text { Computational overhead is not } \\
\text { taken into consideration }\end{array}$ \\
\hline [3] & $\begin{array}{l}\text { Anja Feldmann, et } \\
\text { al }\end{array}$ & 2007 & Clean-slate style & $\begin{array}{l}\text { Clean-Slate, Post-IP, Internet, } \\
\text { network architecture }\end{array}$ & $\begin{array}{l}\text { Control Overhead is not taken } \\
\text { into consideration }\end{array}$ \\
\hline [5] & $\begin{array}{l}\text { Anna Maria Vegni, } \\
\text { et al }\end{array}$ & 2008 & $\begin{array}{l}\text { Home Marketing Atomizer: } \\
\text { Out of the way Sharing of } \\
\text { Home Content material - } \\
\text { without Semi-trusted } \\
\text { Proxies }\end{array}$ & $\begin{array}{l}\text { Property Network, UPnP, } \\
\text { Articles Sharing, Atom }\end{array}$ & $\begin{array}{l}\text { The solution is not considered } \\
\text { to be efficient }\end{array}$ \\
\hline [6] & Van Jacobson, et al & 2009 & $\begin{array}{l}\text { NNC: Using new ways of } \\
\text { routing known as content, } \\
\text { made heavily via IP, we } \\
\text { can simultaneously obtain } \\
\text { scalability, protection and } \\
\text { performance. }\end{array}$ & $\begin{array}{l}\text { Design, Experimentation, } \\
\text { Performance, Security }\end{array}$ & $\begin{array}{l}\text { Because of some architectural } \\
\text { issues the solution is not } \\
\text { scalable and efficient. }\end{array}$ \\
\hline [7] & Zhijia Chen, et al & 2009 & $\begin{array}{l}\text { Large-scale Data } \\
\text { Distribution within } \\
\text { Booming World wide web: } \\
\text { Effectiveness, Bottlenecks } \\
\text { along with Practices }\end{array}$ & $\begin{array}{l}\text { P2P, Services Computing, Bulk } \\
\text { Data, Client Networks. }\end{array}$ & $\begin{array}{l}\text { Computational overhead is not } \\
\text { taken into consideration }\end{array}$ \\
\hline [8] & Hosik Sohn, et al & 2009 & Fuzzy Container Scheme & $\begin{array}{l}\text { UGC, Articles sharing, } \\
\text { household network, information } \\
\text { that is personal }\end{array}$ & $\begin{array}{l}\text { The consumption of contents } \\
\text { is limited over gang of } \\
\text { consumers }\end{array}$ \\
\hline [9] & $\begin{array}{l}\text { TIMO } \\
\text { SUKUVAARA, et } \\
\text { al }\end{array}$ & 2009 & $\begin{array}{l}\text { An wise hybrid wifi traffic } \\
\text { support platform }\end{array}$ & $\begin{array}{l}\text { improving traffic safety, } \\
\text { efficiency and smoothness }\end{array}$ & $\begin{array}{l}\text { Overhead is considered to be } \\
\text { ignored }\end{array}$ \\
\hline [10] & Chih-Lin $\mathrm{Hu}$, et al & 2010 & $\begin{array}{l}\text { Mobile Party } \\
\text { Communication Technique } \\
\text { in Common } \\
\text { Communication Multilevel }\end{array}$ & $\begin{array}{l}\text { cell group connection, mobile } \\
\text { messaging, position tracking, } \\
\text { huge service. }\end{array}$ & $\begin{array}{l}\text { More security plans and } \\
\text { critical cryptography } \\
\text { technologies could well be } \\
\text { examined in addition to } \\
\text { applied in place to strengthen } \\
\text { the machine security in } \\
\text { addition to robustness. }\end{array}$ \\
\hline [19] & $\begin{array}{l}\text { Ould - Maria Vegni, } \\
\text { et al. }\end{array}$ & 2011 & $\begin{array}{l}\text { Hybrid car communications } \\
\text { based on V2V-V2I protocol } \\
\text { switching. }\end{array}$ & $\begin{array}{l}\text { the absolute maximum and } \\
\text { minimum amount bounds of } \\
\text { information propagation and } \\
\text { review performance }\end{array}$ & $\begin{array}{l}\text { Overhead is considered to be } \\
\text { ignored }\end{array}$ \\
\hline
\end{tabular}




\begin{tabular}{|c|c|c|c|c|c|}
\hline [23] & $\begin{array}{l}\text { Alireza Amirshahi, } \\
\text { et al }\end{array}$ & 2011 & Fuzzy Mobility Model & $\begin{array}{l}\text { Internet of Things (IOT); } \\
\text { Commercial Products; Pattern; } \\
\text { Survey; }\end{array}$ & $\begin{array}{l}\text { An adaptive power control } \\
\text { method to improve the } \\
\text { network energy efficiency is } \\
\text { ignored }\end{array}$ \\
\hline [21] & Linjuan Zhang, et al & 2013 & $\begin{array}{l}\text { Multilevel fusion approach, } \\
\text { fuzzy clustering }\end{array}$ & $\begin{array}{l}\text { reducing the network traffic load, } \\
\text { detect road congestion efficiently } \\
\text { with low bandwidth consumption }\end{array}$ & $\begin{array}{l}\text { The solution is not efficient } \\
\text { and scalable }\end{array}$ \\
\hline & Javad Badali,et al & 2013 & $\begin{array}{l}\text { MCDM multi-criteria } \\
\text { decision-making method }\end{array}$ & $\begin{array}{l}\text { VANET ,Data Dissemination, } \\
\text { broadcast storm, fuzzy decision } \\
\text { making }\end{array}$ & $\begin{array}{l}\text { Some of the architectural } \\
\text { issues considered to be } \\
\text { ignored }\end{array}$ \\
\hline$[50]$ & Min Chen, et al & 2014 & $\begin{array}{l}\text { VENDNET: Vehicular } \\
\text { Named Data Network }\end{array}$ & VANET, LTE, NDN, QOS & $\begin{array}{l}\text { Your VANDNET model } \\
\text { might be evaluated underneath } \\
\text { various examples by a huge } \\
\text { number of automobiles, and } \\
\text { freedom patterns, together } \\
\text { with by utilizing prototypes } \\
\text { which can be ignored yet. }\end{array}$ \\
\hline [22] & $\begin{array}{l}\text { Shruti S. } \\
\text { Jamsandeka, et al }\end{array}$ & 2014 & $\begin{array}{l}\text { FIS: Fuzzy Inference } \\
\text { System }\end{array}$ & $\begin{array}{l}\text { fuzzy classification, clustering, } \mathrm{k} \\
\text { means, membership function }\end{array}$ & $\begin{array}{l}\text { The solution is not efficient } \\
\text { and scalable }\end{array}$ \\
\hline [18] & $\begin{array}{l}\text { Treffyn.Koreshoff,et } \\
\text { al }\end{array}$ & 2014 & Internet of Things & $\begin{array}{l}\text { Net of Issues (IOT); Business } \\
\text { Products; Pattern; Survey }\end{array}$ & $\begin{array}{l}\text { The network energy efficiency } \\
\text { is ignored }\end{array}$ \\
\hline [30] & $\begin{array}{l}\text { Fernando Terroso- } \\
\text { Sáenz, et al }\end{array}$ & 2014 & $\begin{array}{l}\text { Visitors Congestion } \\
\text { Recognition With } \\
\text { Sophisticated Event } \\
\text { Digesting }\end{array}$ & $\begin{array}{l}\text { Complex affair processing } \\
\text { (CEP), event-driven structures } \\
\text { (EDA), site visitors information } \\
\text { devices (TISs), vehicular random } \\
\text { network (VANET). }\end{array}$ & $\begin{array}{l}\text { Environmental information } \\
\text { detection is ignored }\end{array}$ \\
\hline [18] & Zhiwei Yan, et al & 2014 & $\begin{array}{l}\text { NDN, Vehicular } \\
\text { Information Network } \\
\text { Architecture }\end{array}$ & $\begin{array}{l}\text { Caching, Internet, Internet of } \\
\text { Things (IOT), mobility } \\
\text { management, named data } \\
\text { networking (NDN), performance. }\end{array}$ & $\begin{array}{l}\text { To address some of the } \\
\text { architectural issues and make } \\
\text { the solution efficient and } \\
\text { scalable }\end{array}$ \\
\hline [31] & Walid Elbreiki, et al & 2015 & NDN,V2V communication & $\begin{array}{l}\text { named data networking, } \\
\text { vehicular ad hoc networks, } \\
\text { vehicle-to-vehicle, naming }\end{array}$ & $\begin{array}{l}\text { Some of the architectural } \\
\text { issues are not taken into the } \\
\text { consideration }\end{array}$ \\
\hline [33] & Xiaoke Jiang, et al & 2015 & $\mathrm{NDN}$ & $\begin{array}{l}\text { NDN, Named Data Networking, } \\
\text { Application }\end{array}$ & $\begin{array}{l}\text { The network energy efficiency } \\
\text { is ignored }\end{array}$ \\
\hline
\end{tabular}

\section{CONCLUSION}

The VANETs paradigm has received a great deal of attention recently. VANETs provides the emergence of various new research areas and one area is most likely the vehicular information network where the large number of vehicles and items possess concerns and massive degrees of information exchanged along with high frequency. The high information management and low communication efficiency incurred in the vehicular information network tend to be challenging for researchers to examine more useful and scalable network architectures and communication schemes. In this paper we have carried out the comparison of various well-known techniques in VANETS. This paper indicates that NDN for VANETS has improved the results when implemented on the available techniques still some issues are there which are un- addressed. We can further improve NDN by further optimizing the decision making so that it produce better results than earlier techniques. So in future we will propose a novel vehicular data network using fuzzy membership functions which will extend the NDN model and support location based forwarding, content aggregation and distributed mobility management.

\section{REFERENCES}

[1] Biswas, Subir, Raymond Tatchikou, and Francois Dion. "Vehicle-to-vehicle wireless communication protocols for enhancing highway traffic safety." Communications Magazine, IEEE 44.1 (2006): 74-82.

[2] Koponen, Teemu,Mohit Chawla and "A data-oriented (and beyond) network architecture." ACM SIGCOMM 
Computer Communication Review. Vol. 37. No. 4. ACM, 2007.

[3] Feldmann, Anja. "Internet clean-slate design: what and why?." ACM SIGCOMM Computer Communication Review 37.3 (2007): 59-64.

[4] Eriksson, Jakob, Hari Balakrishnan, and Samuel Madden. "Cabernet: vehicular content delivery using WiFi." Proceedings of the 14th ACM international conference on Mobile computing and networking. ACM, 2008.

[5] Belimpasakis, Petros, Seamus Moloney, Vlad Stirbu, and Jose Costa-Requena. "Home media atomizer: remote sharing of home content-without semi-trusted proxies." Consumer Electronics, IEEE Transactions on 54, no. 3 (2008): 1114-1122.

[6] Jacobson, Van, Diana K. Smetters, James D. Thornton, Michael F. Plass, Nicholas H. Briggs, and Rebecca L. Braynard. "Networking named content." In Proceedings of the 5th international conference on Emerging networking experiments and technologies, pp. 1-12. ACM, 2009.

[7] Chen, Zhijia, Yang Zhao, Chuang Lin, and Qingbo Wang. "Accelerating large-scale data distribution in booming internet: effectiveness, bottlenecks and practices." Consumer Electronics, IEEE Transactions on 55, no. 2 (2009): 518-526.

[8] Sukuvaara, Timo, and Pertti Nurmi. "Wireless traffic service platform for combined vehicle-to-vehicle and vehicle-to-infrastructure communications." Wireless Communications, IEEE 16.6 (2009): 54-61.ssss

[9] Hu, Chih-Lin, Chien-An Cho, Chang-Jung Lin, and Chen-Wei Fan. "Design of mobile group communication system in ubiquitous communication network." Consumer Electronics, IEEE Transactions on 56, no. 1 (2010): 88-96.

[10] Wang, Lucas, Ryuji Wakikawa, Romain Kuntz, Rama Vuyyuru, and Lixia Zhang. "Data naming in vehicle-tovehicle communications." In Computer Communications

[11] Fitzgerald, Emma, and Björn Landfeldt. "A system for coupled road traffic utility maximisation and risk management using VANET." Intelligent Transportation Systems (ITSC), 2012 15th International IEEE Conference on. IEEE, 2012.

[12] Ahlgren, Bengt, Christian Dannewitz, Claudio Imbrenda, Dirk Kutscher, and Börje Ohlman. "A survey of information-centric networking." Communications Magazine, IEEE 50, no. 7 (2012): 26-36.

[13] Veltri, Luca, et al. "A novel batch-based group key management protocol applied to the Internet of Things." Ad Hoc Networks 11.8 (2013): 2724-2737.Chen, Min, Dung Ong Mau, Yin Zhang, Tarik Taleb, and Victor CM Leung. "VENDNET: VEhicular Named Data NETwork." Vehicular Communications 1, no. 4 (2014): 208-213.

[14] Benamar, Nabil, Kamal D. Singh, Maria Benamar, Driss El Ouadghiri, and Jean-Marie Bonnin. "Routing protocols in vehicular delay tolerant networks: A comprehensive survey." Computer Communications 48 (2014): 141-158.
[15] Jabbarpour, Mohammad Reza, Ali Jalooli, Erfan Shaghaghi, Rafidah Md Noor, Leon Rothkrantz, Rashid Hafeez Khokhar, and Nor Badrul Anuar. "Ant-based vehicle congestion avoidance system using vehicular networks." Engineering Applications of Artificial Intelligence 36 (2014): 303-319.

[16] Borgia, Eleonora. "The Internet of Things vision: Key features, applications and open issues." Computer Communications 54 (2014): 1-31.

| IJCA ${ }^{T M}$ : www.ijcaonline.org 1ly, and Young-Jin Park. "A tion Network Architecture based on Named Data Networking (NDN)."

[18] Vegni, Anna Maria, and Thomas DC Little. "Hybrid vehicular communications based on V2V-V2I protocol switching." International Journal of Vehicle Information and Communication Systems 2.3-4 (2011): 213-231.

[19] Koreshoff, Treffyn Lynch, Toni Robertson, and Tuck Wah Leong. "Internet of things: a review of literature and products." Proceedings of the 25th Australian ComputerHuman Interaction Conference: Augmentation, Application, Innovation, Collaboration. ACM, 2013.

[20] Zhang, Linjuan, et al. "A multilevel information fusion approach for road congestion detection in VANETs." Mathematical and Computer Modelling 58.5 (2013): 1206-1221

[21] Dighe, Nikhil S., Jun Zhuang, and Vicki M. Bier. "Secrecy in defensive allocations as a strategy for achieving more cost-effective attacker deterrence." International Journal of Performability Engineering 5.1 (2009): 31 .

[22] Amirshahi, Alireza, Mahmood Fathi, Morteza Romoozi, and Mohammad Assarian. "A fuzzy realistic mobility model for vanet." IJCSI International Journal of Computer Science Issues 8, no. 5 (2011).

[23] Agrawal, Ankita, Aditi Garg, Niharika Chaudhiri, Shivanshu Gupta, Devesh Pandey, and Tumpa Roy. "Security on Vehicular Ad Hoc Networks (VANET): A Review Paper." GLNA Institute of Technology, Mathura, International Journal of Emerging Technology and Advanced Engineering 3, no. 1 (2013).

[24] Sakhreliya, Sumegha, and Neha Pandya. "A Review on Security Issues and Its Solution's Overhead in VANETs." International Journal of Scientific and Research Publications: 206.

[25] Li, Fan, and Yu Wang. "Routing in vehicular ad hoc networks: A survey." Vehicular Technology Magazine, IEEE 2.2 (2007): 12-22.

[26] Singh, Anuradha, and Mintu Singh. "A Comprehensive Review on Vehicular Ad hoc Network."

[27] Mahendri, Neha Sawal. "A Survey on Vehicular Ad-hoc Networks (VANETs)."

[28] Narang, Ghanishtha, and Yogesh Juneja. "Review on classification of different VANET Protocols based on routing information."

[29] Tal, Irina, and Gabriel-Miro Muntean. "Using fuzzy logic for data aggregation in vehicular networks." Proceedings of the 2012 IEEE/ACM 16th International Symposium on Distributed Simulation and Real Time Applications. IEEE Computer Society, 2012. 